\title{
Increased c-fos Expression in Spinal Neurons after Irritation of the Lower Urinary Tract in the Rat
}

\author{
Lori A. Birder and William C. de Groat \\ University of Pittsburgh School of Medicine, Department of Pharmacology, Pittsburgh, Pennsylvania 15261
}

This study utilized neuronal c-fos expression to examine the spinal pathways involved in processing nociceptive and nonnociceptive afferent input from the lower urinary tract (LUT) of the urethane-anesthetized rat. $\mathbf{C}$-fos protein was detected immunocytochemically in only a small number of cells $(<2$ cells $/ L_{6}$ section) in control animals. However, chemical irritation with $1 \%$ acetic acid or mechanical stimulation of the LUT markedly increased the number of c-fos-positive neurons (56-180 cells $/ L_{6}$ section) in four regions of the caudal lumbosacral $\left(L_{6}-S_{1}\right)$ spinal cord: medial dorsal horn (MDH), lateral dorsal horn, dorsal commissure (DCM), and sacral parasympathetic nucleus (SPN). Only small numbers of c-fospositive cells were detected in rostral lumbar segments, a region that is thought to receive nociceptive input from the LUT via afferent pathways in sympathetic nerves. The distribution of $c$-fos-positive cells in the $L_{6}$ spinal cord varied according to the stimulus (i.e., urethral catheter, bladder distension, or chemical irritation). Distension of the urinary bladder increased the number of c-fos-positive cells malnly In DCM and SPN regions of the cord. In contrast, irritation of the LUT increased c-fos expression largely in DCM and MDH areas. Spinal cord transection $\left(\mathrm{T}_{8}\right.$ level) did not alter the $\mathrm{c}$-fos expression induced by a catheter or chemical irritation, indicating that gene expression was mediated by spinal pathways. Denervation experiments showed that c-fos expression was induced by activation of afferent pathways in the pelvic and pudendal nerves. These results suggest that neurons in several regions of the spinal cord are involved in processing afferent input from different parts of the LUT. Neurons in the DCM appear to have an important role since they respond to both nociceptive and non-nociceptive inputs and to visceral (pelvic nerve) and somatic (pudendal nerve) afferent pathways. Thus, these neurons may be involved in the mechanisms of visceral-somatic referred pain.

Electrophysiological studies have identified several types of afferent neurons innervating the urinary bladder (Janig and Morrison, 1986; Janig and Koltzenburg, 1990). One type is mechanosensitive and responds to bladder distension or bladder contractions. In the cat, these afferent neurons have myelinated axons and are activated by both low (non-nociceptive) and high

\footnotetext{
Received Mar. 9, 1992; revised July 7, 1992; accepted July 13, 1992.

This study was supported by NIH Grants DK-37241 and DK-42369. L.A.B. is a recipient of an advanced predoctoral fellowship in pharmacology from the Pharmaceutical Manufacturer's Association Foundation. We thank Dr. R. Pagano for help with statistical analysis.

Correspondence should be addressed to L. A. Birder at the above address.

Copyright (C) 1992 Society for Neuroscience $0270-6474 / 92 / 124878-12 \$ 05.00 / 0$
}

(nociceptive) intravesical pressures. Other types of afferents do not respond to bladder distension but are activated by cold temperatures (Fall et al., 1990) or chemical irritation of the bladder mucosa (Janig and Koltzenburg, 1990). The latter types have unmyelinated axons and are believed to have primarily nociceptive functions (Habler et al., 1990).

The majority of bladder afferent neurons are located in the sacral or caudal lumbosacral dorsal root ganglia and send axons into the periphery through the pelvic nerves (Sharkey et al., 1983; de Groat, 1986; Steers et al., 1991; Keast and de Groat, 1992). A smaller group of bladder afferent neurons that are located in rostral lumbar dorsal root ganglia have axons that travel in sympathetic (hypogastric) nerves (Steers et al., 1991; Keast and de Groat, 1992).

WGA-HRP tracing studies in the rat revealed that in the $\mathrm{L}_{6}-$ $\mathrm{S}_{1}$ spinal cord, bladder afferent neurons project to discrete regions of the dorsal horn and intermediate gray including Lissauer's tract, lateral lamina I, laminae V-VII, and the dorsal commissure (DCM) (Jansco and Maggi, 1987; Steers et al., 1991). Similar afferent projections have been noted in the cat (de Groat, 1986; de Groat et al., 1986). Neurons at these sites in the spinal cord respond to non-nociceptive mechanical stimulation of the urinary bladder (de Groat, 1971; de Groat et al., 1981; McMahon and Morrison, 1982a; Honda, 1985). Some of these spinal neurons send axons rostrally into the lateral funiculi and are presumably tract neurons that transmit information to supraspinal centers involved in visceral sensation or in the initiation of voiding reflexes (de Groat et al., 1979; McMahon and Morrison, 1982b). The spinal processing of nociceptive input from the urinary bladder has not been analyzed using electrophysiological techniques. However, WGA-HRP tracing experiments indicate that capsaicin-sensitive, small-diameter bladder afferents, presumably including the nociceptive population, exhibit central projections similar to those of non-nociceptive afferents (Steers et al., 1991).

The present study was undertaken to obtain more detailed information about the spinal pathways that process nociceptive and non-nociceptive afferent input from the lower urinary tract (LUT) of the rat. Spinal neurons activated by bladder distension or chemical irritation of the LUT were identified by increased expression of c-fos, an immediate-early gene (Curran, 1988). Previous studies have shown that an increase in c-fos protein in spinal neurons can be detected with immunocytochemical techniques within a few hours following chemical irritation of somatic structures, such as the paw (Hunt et al., 1987; Menetrey et al., 1989; Bullitt, 1990). The present experiments revealed that noxious or non-noxious stimulation of the LUT increased c-fos expression in $L_{6}-S_{1}$ spinal neurons in discrete regions of 


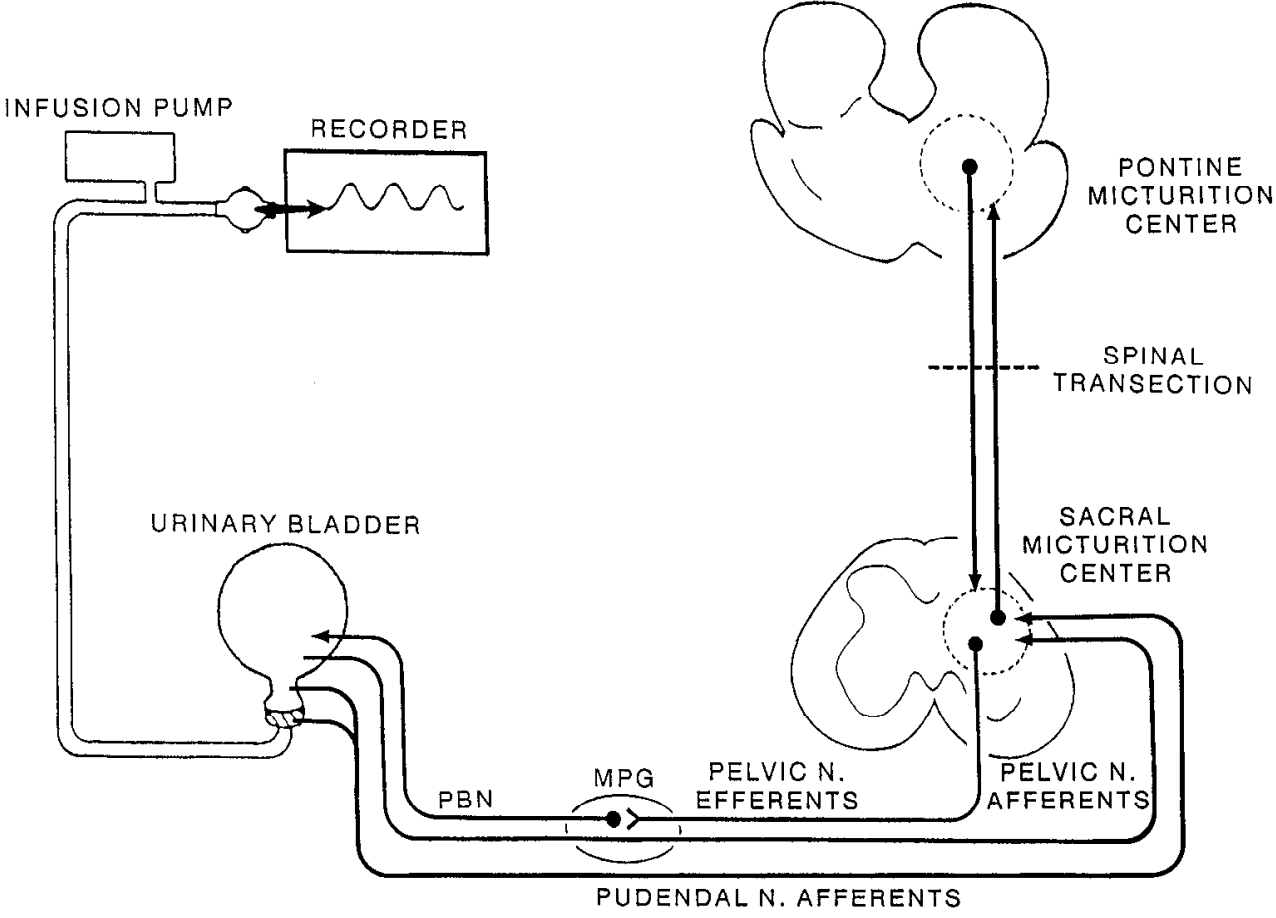

Figure 1. Diagram showing the organization of the spinobulbospinal micturition reflex pathway and the method for infusing fluids into the urinary bladder via a transurethral catheter. The urethral outlet was open during a continuous cystometrogram to allow fluid to drain out from the bladder or was closed by a tie at the urethral orifice to allow recordings of isovolumetric bladder contractions. In some preparations, the spinal cord was transected to block the micturition reflex pathways. $P B N$, postganglionic bladder nerves; $M P G$, major pelvic ganglion. the cord that overlap with those areas receiving afferent input from the urinary bladder. It is noteworthy, however, that more rostral lumbar segments that also receive sympathetic afferent projections from the LUT did not exhibit c-fos-positive neurons.

Preliminary results of some of these observations have been reported previously (Birder et al., 1989, 1990).

\section{Materials and Methods}

Experiments were performed on 92 urethane-anesthetized $(1.2 \mathrm{mg} / \mathrm{kg}$, i.p.) adult female Wistar rats; 78 had intact spinal cords and 14 had spinal transections at the $\mathrm{T}_{8}$ level 4-7 d prior to the experiment. Experiments were also conducted in rats $(N=14)$ with intact spinal cords in which either pelvic or pudendal nerves were bilaterally transected 1 weck prior to the experiments.

The urinary bladder was catheterized through the urethra to infuse fluids and to measure bladder pressure. Intravesical pressure was measured using a strain gauge transducer and recorded on a polygraph (Fig. 1). Two different preparations were used for physiological studies: (1) animals in which the urethral outlet remained open (continuous infusion) or (2) animals in which the urethra was closed via a ligature placed around the urethral orifice (isovolumetric conditions). In rats with an intact spinal cord, physiological saline solution or a chemical irritant ( $1 \%$ acetic acid in physiological saline) was infused into the bladder $(0.12 \mathrm{ml} / \mathrm{min})$ for a $2 \mathrm{hr}$ period. When the urethra was open, the infusion solution could leak out or be expelled during a bladder contraction, thereby preventing overdistension of the bladder. Mineral oil was applied to the area around the urethral orifice to eliminate the possibility of chemical irritation of the perincal skin and vaginal mucosa in this region. When the bladder outlet was closed, the chemical irritant was infused $(0.12 \mathrm{ml} / \mathrm{min})$ until the peak of the first bladder contraction, at which time the infusion was stopped, and the bladder was maintained under isovolumetric conditions. Rhythmic bladder contractions then continued for the remainder of the experiment. The volume necessary to induce the first bladder contraction will be termed the micturition volume threshold (Fig. 1). In spinal animals, the bladders did not exhibit reflex contractions and were unable to expel fluids; thus, to avoid overdistension, the bladders were partially filled with $1 \mathrm{ml}$ of irritant solution and maintained at this volume. Two hours after exposure to the irritant, when the number of c-fos-positive cells in the spinal cord had reached a maximum (Birder et al., 1989), the animals were killed via intracardiac perfusion first with Krebs buffer followed by $8 \%$ para- formaldehyde fixative. Alternate sections $(42 \mu \mathrm{m})$ of the spinal cord $\left(\mathrm{L}_{1}-\mathrm{S}_{2}\right)$ were processed by an avidin-biotin method for the $\mathrm{c}$-fos protein (Hsu ct al., 1981) using antibodics either purchased from Cambridge, Inc. (catalog number OA-11-823), or provided by Dr. M. Iadarola (NIH). The two antibodies yielded similar results. Since the animals were killed $2 \mathrm{hr}$ after the onset of urinary tract stimulation, it is likely that the majority of the immunoreactivity with the Iadarola antibody represents fos protein rather than fos-related proteins (Sonnenberg et al., 1989; Sharp et al., 1991; Young et al., 1991). Cells exhibiting c-fos immunoreactivity were counted in four spinal cord regions: medial dorsal horn (MDH), lateral dorsal horn (LDH), dorsal commissure (DCM), and lateral laminae V-VII including the sacral parasympathetic nucleus (SPN) (Fig. 2). The latter region contains preganglionic neurons as well as interneurons and spinal tract neurons.

Counts of c-fos-positive cells are presented as average numbers of cells per section or percentage change in numbers of cells per section. The changes in cell counts were evaluated statistically using analysis of variance (univariate and multivariate with repeated measures) to examine the interactions between preparations (spinal intact or spinal transected) and areas of cord (MDH, LDH, DCM, SPN). The MannWhitney $U$ test was used to analyze differences in distribution of cell

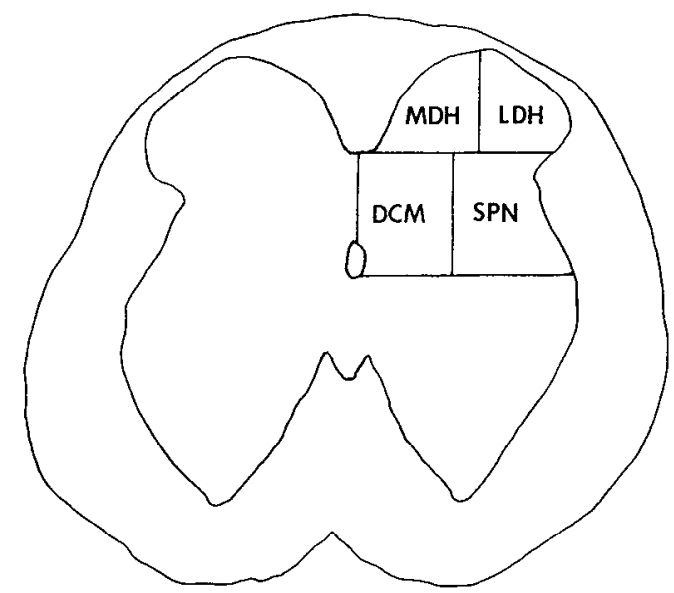

Figure 2. Drawing of a section from the $\mathrm{L}_{6}$ spinal cord in the rat depicting four regions where c-fos-positive neurons were identified following stimulation of the LUT. 


\section{CYSTOMETROGRAM (CMG)}

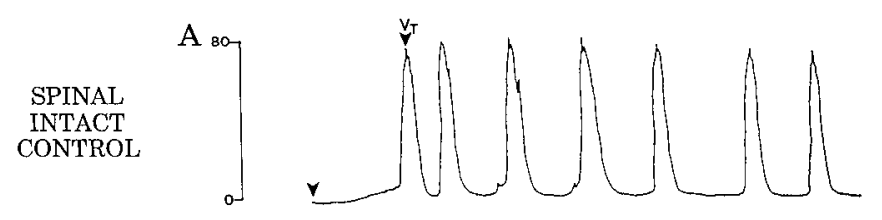

$$
\begin{aligned}
& \text { SPINAL } \\
& \text { INTACT }
\end{aligned}
$$

IRRITANT
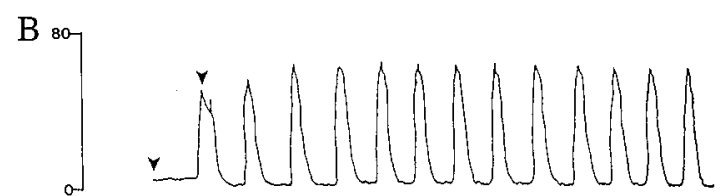

SPINAL
TRANSECTED

TRANSECTED

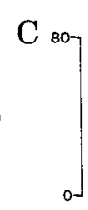

$\checkmark$

experiments was conducted to examine the effects on bladder activity of several chemical irritants (1\% acetic acid, $25 \%$ turpentine, or $100 \%$ xylene) administered intravesically to determine which of these irritants would be most useful for the anatomical studies. Several parameters of bladder activity were evaluated, including (1) the volume threshold for inducing a micturition reflex during slow filling of the bladder, and (2) the frequency and (3) amplitude of rhythmic bladder contractions recorded in the distended bladder under isovolumetric conditions. Although all of the agents were found to enhance bladder activity, acetic acid was most useful since it is water soluble. Turpentine oil and xylene are not water soluble and therefore were difficult to remove from the urinary bladder.

In normal animals with an intact neuraxis, infusion of $1 \%$ acetic acid $(0.12 \mathrm{ml} / \mathrm{min})$ with the urethra either open or closed facilitated bladder reflexes (Fig. 3). In animals with the outlet closed by urethral ligation, chemical irritation decreased the volume threshold by $55 \%$ (range, $14-83 \%$ ) and increased the frequency of isovolumetric contractions by $30 \%$ (range, 6-55\%); however, baseline pressure during filling was unchanged (0-10 $\mathrm{cm} \mathrm{H}_{2} \mathrm{O}$ ), as was the amplitude of bladder contractions. This effect occurred within a few minutes after infusion of the irritant. When examined with the urethral orifice ligated, the effect of irritation persisted for the length of the experiment $(2 \mathrm{hr})$. However, ligating the urethral orifice activated somatic afferents from this region and increased c-fos expression in spinal cord (see below). Therefore, the majority of anatomical experiments were conducted using the continuous cystometrogram with the urethral outlet open. In this preparation, continuous infusion of a chemical irritant decreased by $30 \%$ (range, 19-46\%) the micturition volume threshold and increased by $60 \%$ (range, 35$79 \%$ ) the frequency of bladder contractions. In some animals, bladder contractions ceased approximately 20-30 min after the start of the irritant infusion. The reason for this is not known.

Spinal-transected animal. Transection of the spinal cord at the lower thoracic level in the rat produces an initial bladder areflexia lasting for 1-2 weeks (Mallory et al., 1989). Following this period, bladder reflexes recover. In the anatomical experiments, we wanted to examine c-fos expression in some animals in absence of bladder reflexes; thus, acute spinal animals (4-7 $\mathrm{d}, \mathrm{T}_{8}$ level) were used. In these animals, infusion of 1-2 $\mathrm{ml}$ of saline into the bladder did not evoke reflex bladder contractions or the release of urine around the catheter. Similarly, distension of the bladder with 1-2 $\mathrm{ml}$ of saline under isovolumetric conditions did not evoke reflex contractions. Injection of $1 \%$ acetic acid into the bladder in either experiment also did not increase baseline intravesical pressures, evoke rhythmic contractions, or induce voiding (Fig. 3).

\section{Measure of the noxious action of chemical irritants on urothelial integrity}

Exposure of the urothelium to noxious substances such as acetic acid or dimethyl sulfoxide (DMSO) can produce an acute irritation and break down the urothelial mucosal barrier (Horita and Weber, 1964; Hohlbrugger and Lentsch, 1985). The degree of damage to the mucosal barrier can be determined by measuring the penetration of a dye, indigocarmine, through the urothelium into the bladder wall (Perzin et al., 1991). In the present experiments, indigocarmine uptake was measured in animals whose urinary bladders were exposed to either saline, $1 \%$ acetic acid, or $70 \%$ DMSO for $2 \mathrm{hr}$. The quantity of indigocarmine in the bladder wall was determined by UV spectro-

\section{Results}

\section{Physiological changes induced by chemical irritation of the} LUT

Spinal-intact animals. Since a variety of irritant chemicals can activate nociceptive afferents and induce an inflammatory reaction in the urinary bladder (Maggi et al., 1988; Habler et al., 1990; Morikawa et al., 1990), an initial series of physiological 


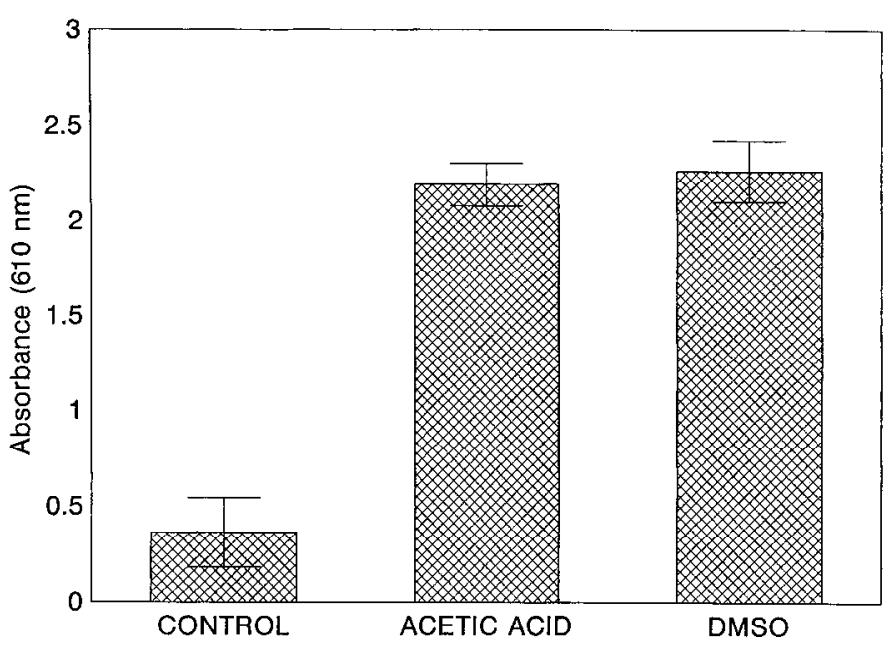

Figure 4. Histogram illustrates the degree of urothelial damage induced by chemical irritation as evidenced by uplake of indigocarmine dye into the bladder wall. The ordinate indicates absorbance of dye in control animals following saline distension $(N=3)$ or in animals in which the urinary bladder was chemically irritated with $1 \%$ acetic acid $(N=3)$ or with $70 \%$ DMSO $(N=2)$ for $2 \mathrm{hr}$. Error bars indicate SE

photometric analyses of the supernatant fluid following homogenization of the bladder. To determine if UV absorbance was proportional to increasing concentrations of dye, measurements were performed on a range of concentrations of indigocarmine in a solution of TCA to establish linearity in the range of $0.001-1 \%$. Control bladders $(N=3)$ exhibited small quantities of dye (Fig. 4), while exposure to acetic acid markedly increased dye concentration above saline controls $(N=3)$. DMSO $(70 \%$ $\mathrm{v} / \mathrm{v}$ solution in saline), which has been shown to enhance the permeability of the urothelium (Horita and Weber, 1964; Hohlbrugger and Lentsch, 1985), also increased the concentration of indigocarmine in the bladder $(N=2)$ (Fig. 4).

Bladders that were exposed to $1 \%$ acetic acid for $2 \mathrm{hr}$ under isovolumetric conditions showed acute signs of inflammation as evidenced by regions of edema, infiltration of polymorphonuclear cells, plasma cells, and mast cells, and disruption of the epithelial layer.

\section{C-fos immunocytochemistry: spinal-intact preparation}

Preliminary experiments to establish optimal conditions. A number of preliminary studies were conducted to determine (1) the influence of prior surgical procedures on the baseline levels of c-fos, (2) the optimal interval following exposure to a chemical irritant for killing the animals, (3) the optimal duration of exposure to the irritant, (4) the type of anesthetic that would be most appropriate for studying c-fos expression, and (5) the segmental distribution of the c-fos-positive cells.

In control animals $(N=5)$ that were anesthetized with urethane but not subjected to any other treatment, the number of c-fos-positive cells in the lumbosacral spinal cord was low (2 cells/section). Animals in which either the pelvic or pudendal nerves were bilaterally transected exhibited small increases in the number of c-fos-positive cells in the $\mathrm{L}_{5}-\mathrm{S}_{1}$ spinal cord (mean, 2.5 and 10.5 cells/section, respectively) 1 week after nerve transections. Infusion of $1 \%$ acetic acid into the bladder via a urethral catheter markedly increased the number of c-fos-positive cells in the $\mathrm{L}_{5}-\mathrm{S}_{1}$ spinal cord (range, $42-187$ cells/section) but produced relatively small increases (range, $4-15$ cells/section)

\section{C-FOS DISTRIBUTION IN THE RAT SPINAL CORD}

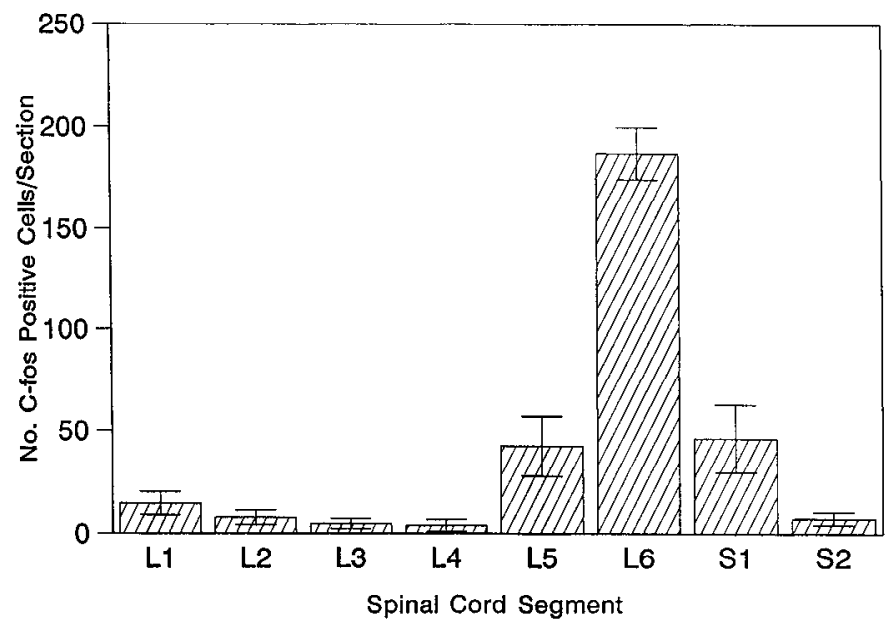

Figure 5. Histogram showing the segmental distribution of c-fos-positive cells (number/section) in the rat spinal cord $\left(\mathrm{L}_{1}-\mathrm{S}_{2}\right)$ after chemical irritation of the LUT $(N=7)$. Error bars indicate SE.

in adjacent segments $\left(\mathrm{L}_{1}-\mathrm{L}_{4}, \mathrm{~S}_{2}\right)$ (Fig. 5). The c-fos immunoreactivity was detected in the nucleus of the cells as reported by other investigators (Fig. 6) (Weinberg, 1985; Curran, 1988; Sager et al., 1988; Sassone-Corsi et al., 1988).

Previous studies using noxious somatic stimuli in spinal-intact, unanesthetized rats have demonstrated that the increased expression of c-fos in spinal neurons was a transient phenomenon reaching a maximum in a few hours and decaying within $24 \mathrm{hr}$ (Hunt et al., 1987). In the present experiments, a small set of animals was killed at various times ( $30 \mathrm{~min}$ to $24 \mathrm{hr}$ ) after bladder irritation ( $1 \%$ acetic acid) to determine the optimum time for detecting c-fos protein in urethane-anesthetized preparations. A large number of cells was detected after continuous exposure to the irritant for $1-2 \mathrm{hr}$, but the numbers declined at $6 \mathrm{hr}$ and were almost back to control levels $24 \mathrm{hr}$ after exposure (Fig. 7). Thus in the remainder of the experiments, animals were killed $2 \mathrm{hr}$ after the initiation of noxious or non-noxious stimulation in the LUT.

The irritant was also applied for $30 \mathrm{~min}$ or $2 \mathrm{hr}$ to determine whether the duration of the stimulus altered the number of $c$ fos-positive cells in the $L_{6}$ segment. In one group of animals, after a 30 min exposure the irritant was flushed out of the bladder by slowly infusing $2 \mathrm{ml}$ of saline and the animals were maintained for an additional $1.5 \mathrm{hr}$ before death. The number of c-fos-positive cells in these animals was $75 \%$ (144 cells/section) of the number in animals exposed to irritant for $2 \mathrm{hr}(183$ cells/ section). It was concluded that duration of irritation would not be a critical factor at intervals greater than $30 \mathrm{~min}$. A $2 \mathrm{hr}$ duration was used in the remainder of the experiments.

Three anesthetics were studied in spinal-intact animals. No differences were noted in the number of c-fos-positive cells induced by chemical irritation of the urinary bladder in urethane- $(1.2 \mathrm{gm} / \mathrm{kg}$, i.p. $)$ and halothane- $(1 \% ; N=2)$ anesthetized animals. However, pentobarbital anesthesia $(40 \mathrm{mg} / \mathrm{kg}$, i.p.; $N$ $=2$ ) completely suppressed c-fos in all regions of the $L_{5}-S_{1}$ spinal cord. Urethane anesthesia was used in the remainder of the experiments. 
A

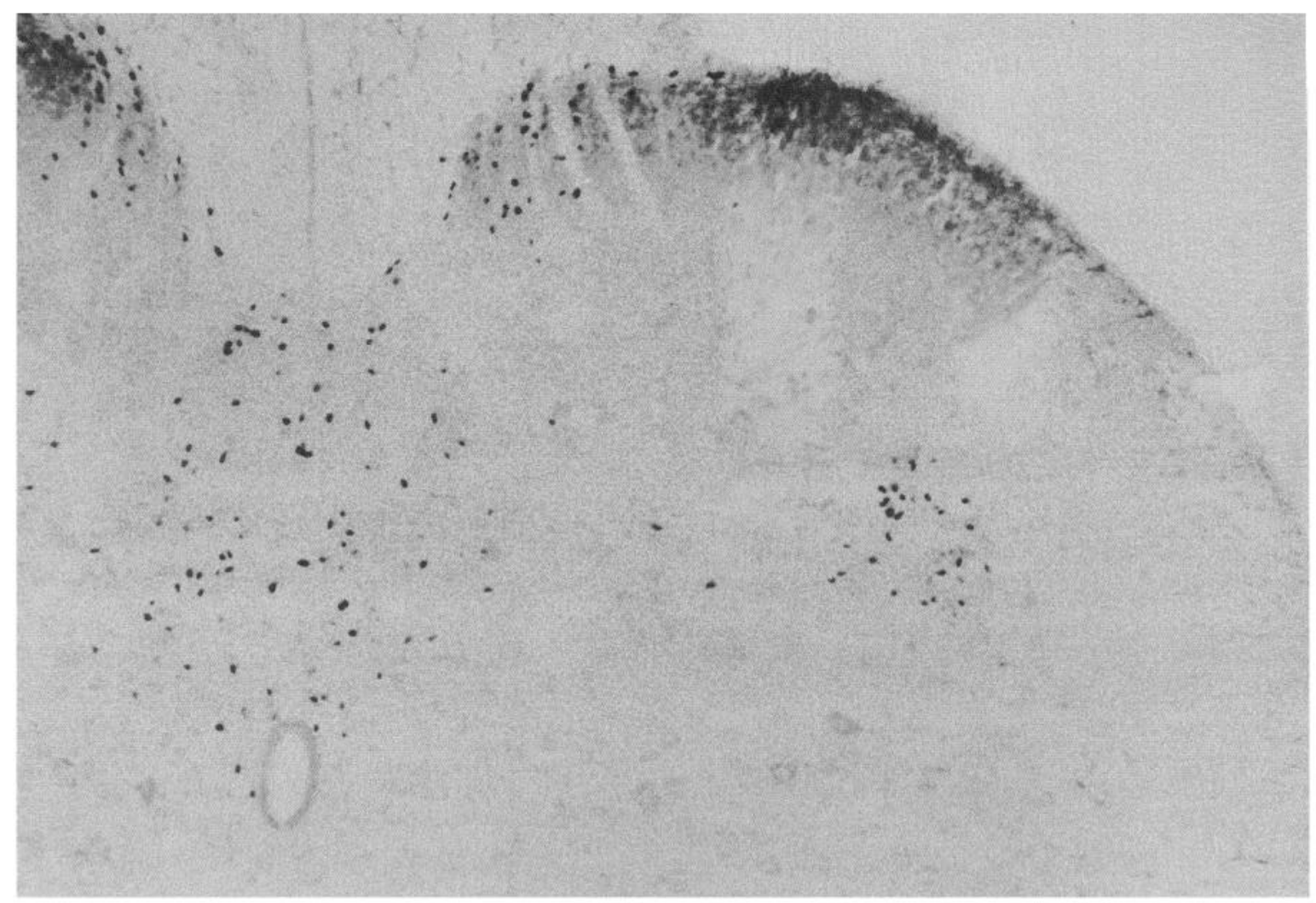

B

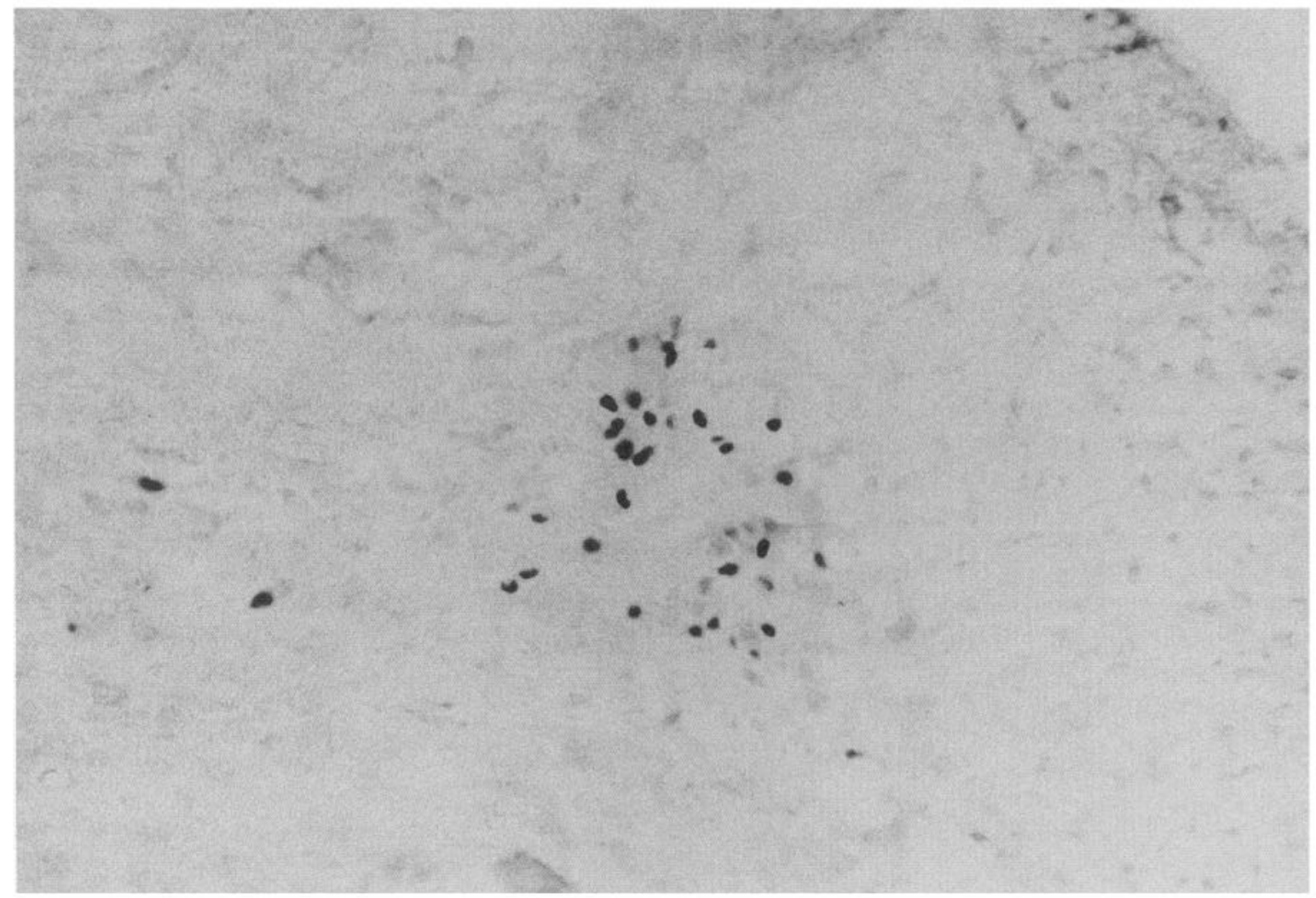


In contrast to the segmental distribution of c-fos in spinal cord neurons after LUT irritation, somatic irritation induced by injection of a $10 \%$ buffered formalin solution into the left rear footpad of the rat increased c-fos in cells mainly in the $\mathrm{L}_{4}-$ $\mathrm{L}_{s}$ spinal cord (average, 40-60 cells/section) (Fig. 8). The cells were distributed throughout the MDH (laminae I-V) ipsilateral to the injection site, as noted previously by other investigators (Hunt et al., 1987; Menetrey et al., 1989; Bullitt, 1990).

Stimuli inducing c-fos expression. A series of experiments were conducted in which the urethral outlet was open and the bladder could empty. In these experiments, fluid was infused continuously $(0.12 \mathrm{ml} / \mathrm{min})$ into the bladder through a urethral catheter. Saline infusion induced voiding reflexes at $2-5 \mathrm{~min}$ intervals. Infusion of an irritant induced bladder hyperreflexia, increased the frequency of voiding, and typically produced a constant slow leak of fluid. This is most likely indicative of a tonically contracted bladder. At least three aspects of the experimental preparation could contribute to an increase in c-fos expression following manipulation of the LUT: (1) insertion of a catheter through the urethra into the bladder, (2) distension of the bladder by the infused solution, (3) chemical irritation of the bladder and urethral mucosa. The influence of each of these stimuli was examined by conducting control experiments in which (1) a catheter was inserted for $2 \mathrm{hr}$ or (2) saline was slowly infused through a catheter for $2 \mathrm{hr}$.

The insertion of a catheter produced a considerable increase in the number of $c$-fos cells $\left(56 \pm 9.6\right.$ cells/section) in the $\mathrm{L}_{6}$ segment, and slow infusion of saline through the catheter further increased the number $(128 \pm 4.1$ cells/section $)$. Infusion of acetic acid increased the number to an average total of $183 \pm 26$ cells/section (Table 1, Fig. 9). Thus, the response to chemical irritation must include a substantial component due to mechanical stimulation of bladder and urethral afferents; that is, $30 \%$ of the number of c-fos-positive cells is attributable to mechanical stimulation by the catheter, $33 \%$ to bladder distension and/or reflex contractions or voiding, and $37 \%$ to chemical irritation.

Topographical distribution of c-fos-positive cells. Following chemical irritation, c-fos-positive cells were located in four areas of the spinal cord: MDH, LDH, DCM, and SPN. No cells were present in the ventral horn. The distribution of c-fospositive cells in four regions of the $\mathrm{L}_{6}$ segment of the spinal cord was determined for each stimulus (i.e., catheter, catheter plus saline infusion, and catheter plus acetic acid infusion). The majority of cells activated by insertion of a catheter occurred in the $\mathrm{MDH}(42.9 \%)$ and DCM (40.9\%) areas, whereas the cells activated by saline infusion through the catheter occurred in DCM (42.2\%), SPN (29.5\%), and MDH (25.6\%). Infusion of acetic acid solution induced c-fos expression primarily in cells in the DCM (43.5\%), SPN (21.9\%), and MDH (27.4\%).

To estimate the specific contribution of (1) tension receptor afferents activated by distension and reflex bladder contractions and (2) nociceptive afferents activated by acetic acid, a process of sequential subtraction was used. For example, the numbers of cells in each region induced by the catheter $\left(N_{c}\right)$ were subtracted from the numbers induced by catheter plus saline infusion $\left(N_{c}+N_{s}\right)$ to estimate the numbers attributable to saline

\section{TIME COURSE OF C-FOS EXPRESSION AFTER LUT IRRITATION}

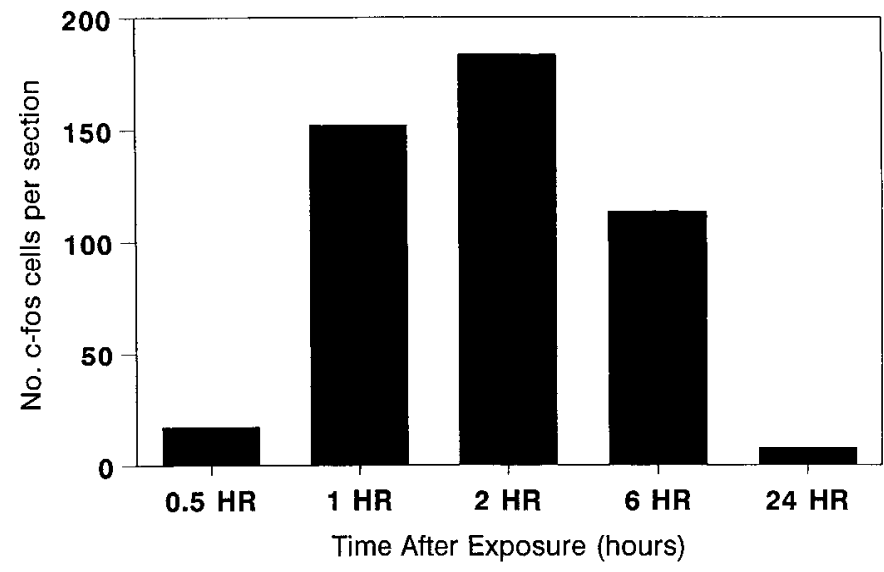

Figure 7. Histogram showing the number of c-fos-positive cells per section in the $\mathrm{L}_{6}$ rat spinal cord, $30 \mathrm{~min}$ to $24 \mathrm{hr}$ after LUT irritation.

infusion alone $\left(N_{s}\right)$. Similarly, the numbers attributable to chemical irritation alone $\left(N_{i}\right)$ were obtained by subtracting $N_{c}+N_{s}$ from the numbers produced by catheter plus infusion of irritation solution $\left(N_{i}+N_{c}+N_{s}\right)$. These calculations revealed that saline infusion that activated repeated micturition reflexes produced a cell distribution that differed significantly from that produced by chemical irritation. While the DCM region contained a similar percentage of neurons following both stimuli $(41 \%$ and $48 \%$ ), the SPN area had a higher percentage of cells following saline distension ( $41 \%$ vs $9.5 \%$; $p<0.05)$. On the other hand, the LDH and MDH regions had significantly $(p<$ 0.05 ) higher percentages of neurons following chemical irritation (Fig. 9, Table 1).

Input from pelvic and pudendal afferents. Afferent pathways from the LUT to the $\mathrm{L}_{6}-\mathrm{S}_{1}$ spinal cord pass through the pelvic and pudendal nerves (de Groat and Steers, 1990). Nerve transection experiments were conducted to determine the relative contributions of pathways in each of these nerves to the chemical irritation-induced c-fos expression in the spinal cord.

Experiments were conducted in animals with either pelvic ( $N$ $=5)$ or pudendal $(N=8)$ nerves transected bilaterally 1 week prior to infusion of $1 \%$ acetic acid via a transurethral catheter. Nerve transections did not induce c-fos expression as noted following transections of the trigeminal (Sharp et al., 1989) and sciatic nerves (Chi et al., 1990). However, in pelvic nerve-transected animals, the number of c-fos-positive cells induced by urinary tract irritation was reduced to $39 \%$ of control ( $72 \pm 20$ cells/section) and the cells were located primarily in the DCM and MDH regions of the cord: DCM (46\%), MDH (33.6\%), and SPN (18.6\%). In the pudendal nerve-transected animals, the number of cells was reduced to $47 \%$ of control $(88 \pm 16$ cells/ section) and the cells were located in DCM (48.4\%), SPN (32.6\%), and $\mathrm{MDH}(11 \%)$. The percentages of cells in the MDH, SPN,

Figure 6. Bright-field photomicrographs of an $\mathrm{L}_{6}$ spinal cord section from the rat showing the distribution of c-fos-positive neurons after LUT irritation. $A$ depicts cells in dorsal horn, DCM region, and SPN area. $B$ is a photomicrograph at a higher magnification depicting cells in the SPN region. Scale bars: $A, 110 \mu \mathrm{m} ; B, 55 \mu \mathrm{m}$. 
Figure 8. A, Camera lucida drawings from $\mathrm{L}_{4}-\mathrm{S}_{2}$ rat spinal cord showing cfos immunoreactivity localized to four spinal cord regions after LUT irritation. $B$, Camera lucida drawings from $\mathrm{L}_{3}-\mathrm{S}_{1}$ rat spinal cord showing $\mathrm{c}$-fos immunoreactivity localized to the dorsal horn after chemical irritation of the right hindpaw. Each drawing shows the distribution of cells in one representative section from each segment.
A

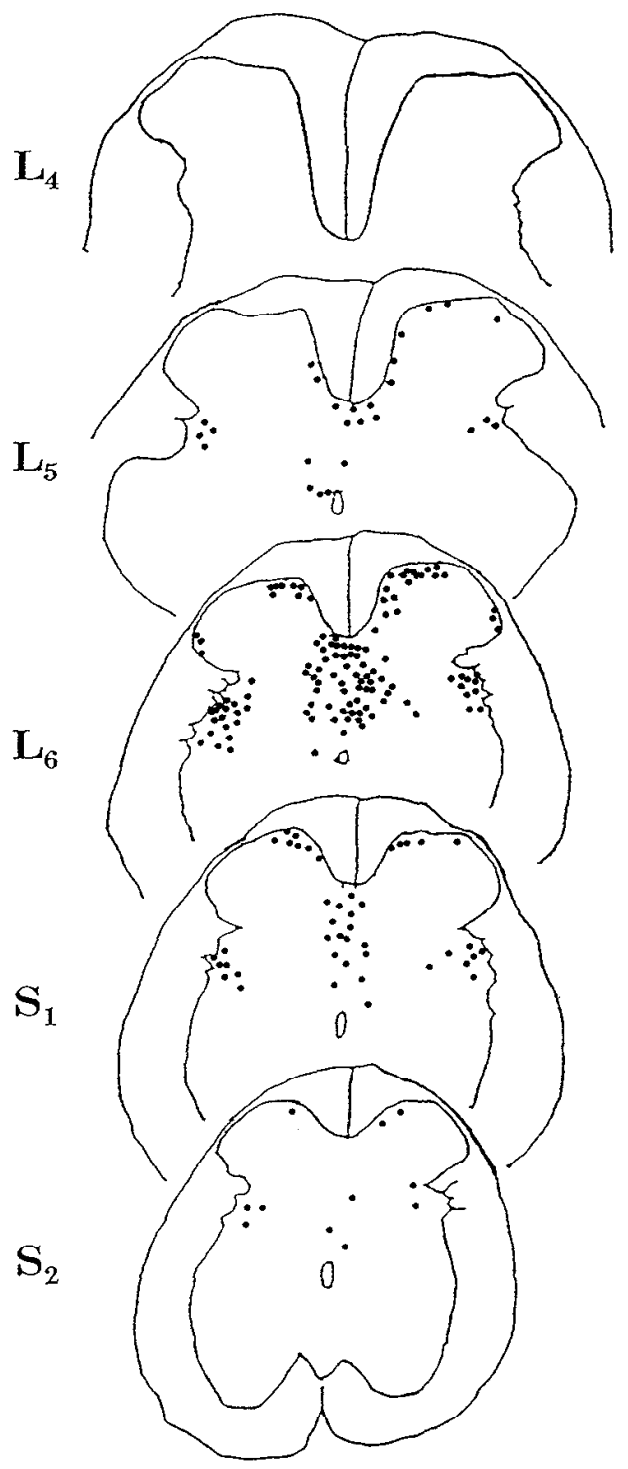

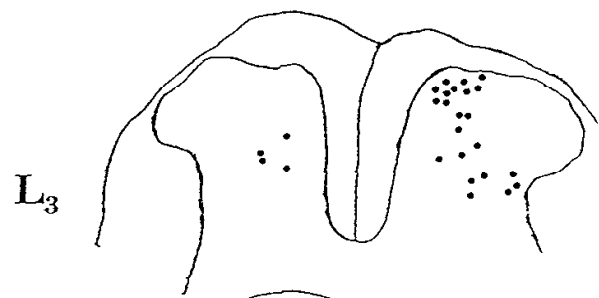

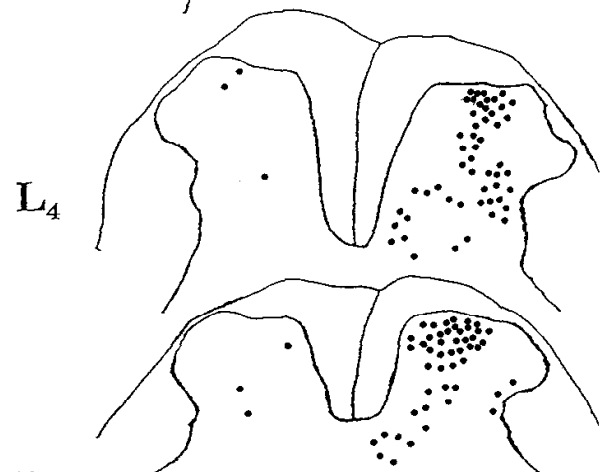

$\mathbf{L}_{5}$

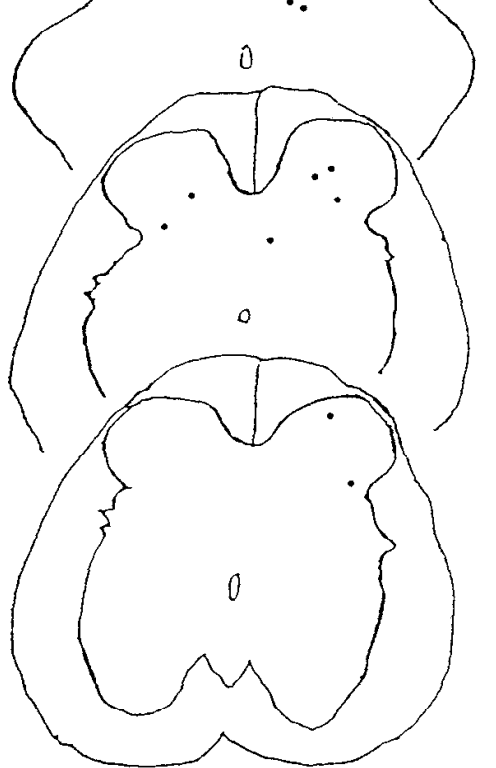

and LDH regions were significantly different in these two groups of animals $(p<0.05)$ (Fig. 10). Animals in which both pelvic and pudendal nerves were bilaterally transected prior to infusion of $1 \%$ acetic acid exhibited low levels of c-fos-positive neurons in the $\mathrm{L}_{6}$ spinal cord ( 6 cells/section), indicating that these nerves contain the majority of the bladder-urethral afferents.

\section{C-fos immunocytochemistry: spinal-transected preparation}

Since approximately $30 \%$ of the c-fos-positive cells following LUT irritation appear to be induced by distension or distensioninduced reflex contractions of the urinary bladder, several types of experiments were conducted to determine whether these cells were activated by reflexes. In order to determine the contribution of activity in the spinobulbospinal micturition reflex pathway (Kuru, 1965; de Groat, 1975; Mallory et al., 1989) to the induction of $\mathrm{c}$-fos in spinal neurons after LUT irritation, an acute spinal-transected preparation was used in which the reflex pathway was interrupted. In spinal-transected animals that were anesthetized with urethane $(1.2 \mathrm{mg} / \mathrm{kg}$, i.p.) but not exposed to a noxious stimulus, $c$-fos protein was not detected in spinal neurons. Placement of a urethral catheter increased the number of cells $(52 \pm 16$ cells/section), whereas instillation of $1 \mathrm{ml}$ of a $1 \%$ acetic acid solution into the urinary bladder markedly increased c-fos expression in all four areas of the lumbosacral spinal cord (146 \pm 7 cells/section; $N=3$ ). As noted above, these animals did not exhibit large-amplitude reflex bladder contractions in response to the chemical irritant. The total number of c-fos-positive neurons occurring after irritation on the average was $17 \%$ less (range, $0-30 \%$ ) than the number in intact animals; however, this change was not statistically significant $(p>0.05)$.

\section{Serosal irritation}

Previous studies by other investigators revealed that capsaicin applied to the serosal surface of the bladder enhanced reflex bladder contractions (Santicioli et al., 1986) and induced an inflammatory reaction in the bladder (Maggi et al., 1987), which 
was particularly prominent in the region of the bladder neck and proximal urethra. To determine if chemical irritation of serosal afferents can increase c-fos immunoreactivity at the spinal cord level, two groups of animals were tested: (1) control animals in which the urinary bladder was exposed by an abdominal incision and (2) animals in which the bladder was exposed and a $1 \mathrm{~cm}$ cotton square soaked with an irritant $(1 \%$ acetic acid or $2 \%$ capsaicin) was placed on the serosal surface for a period of $2 \mathrm{hr}$. In sham-operated animals, the number of c-fos cells was not significantly increased over that occurring in control animals with the abdomen closed ( 3 cells/section; $N=$ 2). Serosal irritation of the urinary bladder either with acetic acid or with capsaicin did not increase the number of c-fospositive cells over control.

\section{Discussion}

The present experiments revealed that non-nociceptive as well as nociceptive afferent input from the LUT increases c-fos expression in neurons in the lumbosacral spinal cord of the urethane anesthetized rat. The increased $\mathrm{c}$-fos expression occurred in discrete regions of the spinal cord and was initiated via activation of both pelvic and pudendal nerve afferents innervating the urinary bladder and urethra.

The largest numbers of c-fos-positive neurons (183 \pm 26 cells/ section) were detected following chemical irritation of the bladder and urethral mucosa by injecting 1\% acetic acid solution through a urethral catheter. This response reflected the activation of several types of afferent systems including (1) mechanoreceptor afferents responding to the transurethral catheter, (2) mechanoreceptor afferents responding to bladder distension and/ or contractions, and (3) nociceptive afferents responding to chemical irritation of the vesicourethral mucosa. Based on control experiments in which the animals received only a urethral catheter or a catheter plus bladder distension, it is estimated that each of the first two stimuli accounts for approximately $30 \%$ of the total population of c-fos-positive cells in the irritated preparation, whereas chemical irritation activates the remaining $37 \%$ of the cells.

The segmental distribution of c-fos-positive spinal neurons induced by each stimulus (i.e., catheter, bladder distension, chemical irritation) was similar, indicating that nociceptive and non-nociceptive afferents project to the same level of the cord. In each instance, the majority of cells were located in the $\mathrm{L}_{6}-\mathrm{S}_{1}$ segments, which receive afferent input from the pelvic and pudendal nerves (Nadelhaft and Booth, 1984; McKenna and Nadelhaft, 1986). Very few cells were located in rostral lumbar segments $\left(L_{1}-L_{4}\right)$. This was unexpected since it is generally be-

\section{PERCENTAGE OF C-FOS NEURONS INDUCED BY DISTENSION OR IRRITATION}

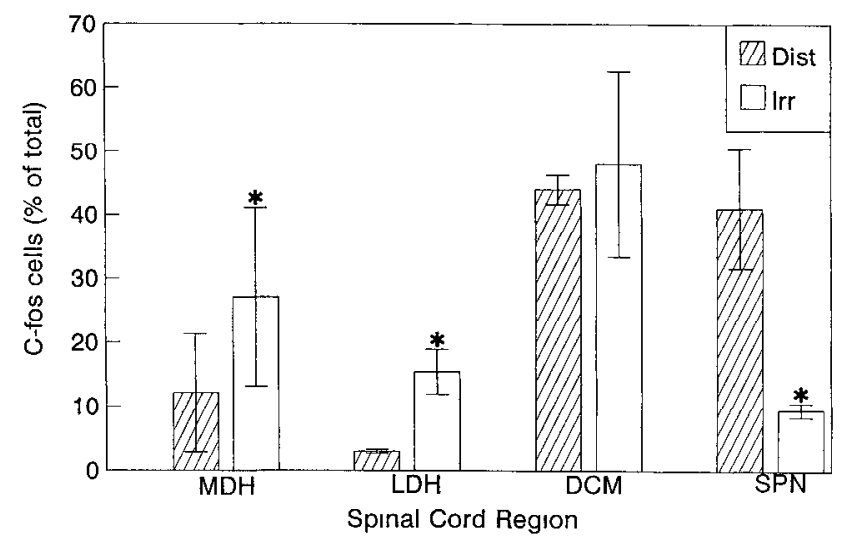

Figure 9. Histogram showing the distribution of c-fos-positive cells in four regions of the $\mathrm{L}_{6}$ spinal cord following bladder distension (Dist, hatched bars; $N=3$ ) or chemical irritation (Irr, open bars; $N=7$ ). Values represent the percentage of the total population of $\mathrm{c}$-fos cells induced by each stimulus. Cells activated by bladder distension were estimated by subtracting the number of cells induced by insertion of a urethral catheter. Cells activated by chemical irritation were estimated by subtracting the number of cells induced by catheter and bladder distension. Error bars indicate SE. Asterisks indicate statistically significant $(p<$ 0.05 ) difference between percentages of cells induced in each area by distension or irritation.

lieved that the rostral lumbar segments receive nociceptive input from the LUT via afferents traveling in sympathetic (hypogastric) nerves (Janig and Morrison, 1986). The localization of c-fos cells in $\mathrm{L}_{6}-\mathrm{S}_{1}$ may simply reflect the larger number of urinary tract afferents projecting to these segments or may indicate that sympathetic afferent pathways to $L_{1}-I_{2}$ are ineffective in inducing c-fos expression. This may be due to differences in synaptic transmission at the two levels of the spinal cord or possibly to the greater susceptibility of nociceptive transmission at $\mathrm{L}_{1}-\mathrm{L}_{2}$ to urethane anesthesia.

It should be noted, however, that the negative results with the c-fos technique are difficult to interpret. For example, although increased expression of $\mathrm{c}$-fos implies that neurons have received synaptic input, the failure to detect $\mathrm{c}$-fos expression does not necessarily mean that neurons have not been synaptically activated. Some neurons may not express c-fos under any condition, or may produce levels of c-fos protein below the threshold for detection with immunocytochemical techniques.

Table 1. Percentage of $c$-fos neurons in regions of the $L_{6}$ spinal cord

\begin{tabular}{lclclc}
$\begin{array}{l}\text { Treat- } \\
\text { ment }\end{array}$ & Total & MDH & LDH & DCM & SPN \\
\hline CATH & 56.4 & $42.9 \pm 7.1$ & $2.0 \pm 1.3$ & $40.9 \pm 2.6$ & $14.4 \pm 7$ \\
DIST & $127.9^{*}$ & $12.1 \pm 9.2^{*}$ & $3.0 \pm 0.3$ & $44.0 \pm 2.3$ & $41.1 \pm 9.4^{*}$ \\
IRR & $183.5^{* *}$ & $27.1 \pm 14^{* *}$ & $15.4 \pm 3.5^{* *}$ & $48.0 \pm 14.6$ & $9.5 \pm 1.1^{* *}$
\end{tabular}

This table indicates the distribution expressed as percentages of c-fos-positive cells in four regions of the $\mathrm{L}_{6}$ spinal cord (MDH, LDH, DCM, and SPN) in a spinal-intact rat following (1) urethral catheterization (CATH; $N=3$ ), (2) bladder distension (DIST; $N=3$ ), and (3) chemical irritation (IRR; $N=7$ ). Cells activated by bladder distension were estimated by subtracting the cells induced by the catheter. Cells activated by chemical irritation were estimated by subtracting those induced by catheter and bladder distension. Total represents the total number of $c$-fos-positive cells per $L_{6}$ section. Asterisks indicate a statistically significant difference in each area $(p<0.05)$ between CATH and DIST $\left(^{*}\right)$ or between DIST and IRR $\left({ }^{* *}\right)$. 


\section{C-FOS EXPRESSION IN THE INTACT VERSUS NERVE TRANSECTED RAT}

Figure 10. Histogram showing the distribution of c-fos-positive cells in four regions of the $\mathrm{L}_{6}$ spinal cord after LUT irritation in animals in which pelvic nerves were bilaterally transected (Pelvic $X$, solid bars) 1 week prior to experimentation and in animals in which pudendal nerves were bilaterally transected (Pud X, hatched bars) 1 week prior to experimentation. Error bars indicate SE. Asterisks indicate statistically significant differences $(p<0.05)$ between the percenlages of cells in each area in the two types of experiments.

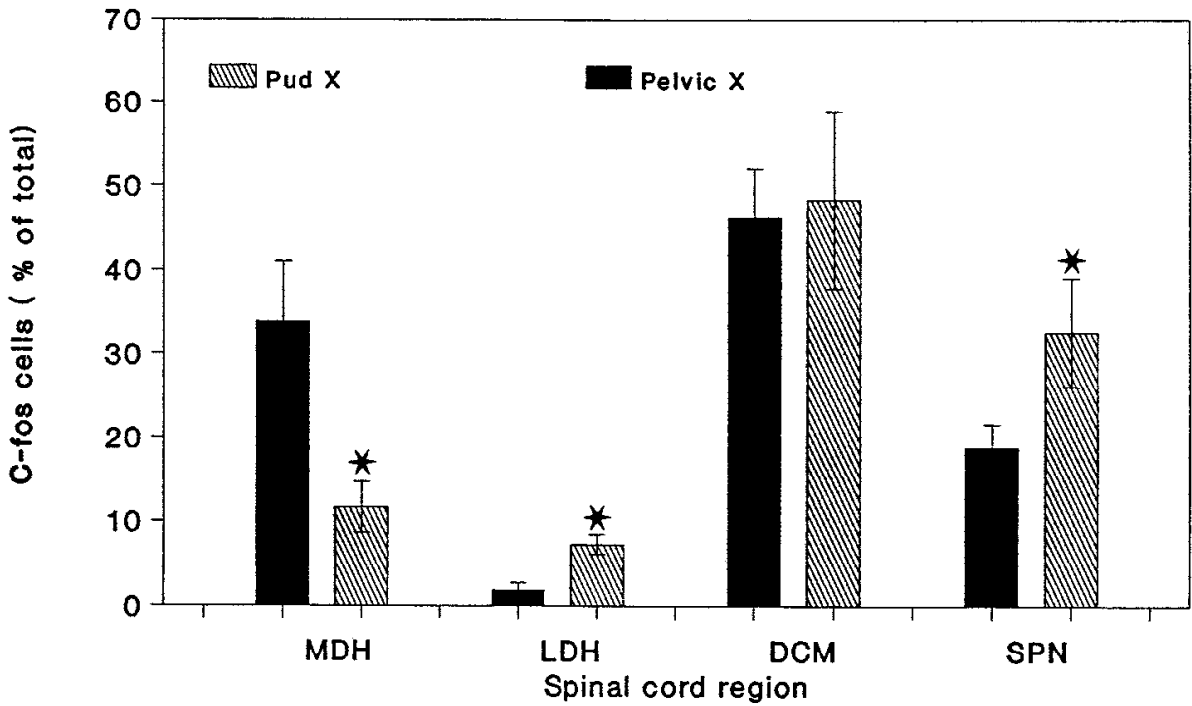

In addition, certain types of synaptic activation may increase c-fos expression, whereas other types may not (e.g., descending activation of spinal inhibitory interneurons, Jones and Light, 1990; light activation of retinal neurons, Sagar and Sharp, 1990).

This problem is clearly illustrated by the failure of sphincter motoneurons in the present experiments to express c-fos in response to a constant infusion of saline into the bladder. Prominent external sphincter contractions occur during voiding in the rat (Maggi et al., 1986; Kruse et al., 1990), indicating that sphincter motoneurons are synaptically activated. However these cells did not exhibit detectable levels of $c$-fos protein. Other reports have also indicated that c-fos levels are low in motoneurons (Jenkins and Hunt, 1991). Thus, it seems reasonable to conclude that increased neuronal levels of c-fos protein do indicate synaptic activation; however, negative immunocytochemical findings do not always indicate an absence of synaptic activity.

Following activation of LUT afferents, c-fos-positive cells were identified in $\mathrm{L}_{6}-\mathrm{S}_{1}$ spinal segments primarily in four areas: MDH, LDH, DCM, and lateral laminae V-VIII in the region of the SPN. These areas also exhibit HRP- or WGA-HRPlabeled afferent projections either from the urinary bladder (Jansco and Maggi, 1987; Steers et al., 1991), or from afferent pathways in the pelvic or pudendal nerves, which contain, respectively, the innervation to the bladder and urethra (Morgan et al., 1981; Nadelhaft and Booth, 1984; McKenna and Nadelhaft, 1986; Thor et al., 1989). Bilateral transection of both pelvic and pudendal nerves almost completely abolished c-fos expression in response to LUT irritation, reducing the number of cells to $3 \%$ of control. Selectively blocking afferent inputs either from the pelvic or pudendal nerves also markedly reduced the number of c-fos-positive neurons to $39 \%$ or $47 \%$ of control, respectively, and altered the distribution of c-fos-positive cells in the four spinal cord regions. These selective denervation experiments indicated that pudendal nerve afferents activated cells primarily in DCM (46\%) and MDH (34\%) regions, whereas pelvic nerve afferents activated cells in DCM (48\%) and SPN (33\%) regions.
The pelvic nerve (a visceral nerve) carries afferents primarily from the bladder and proximal urethra, whereas the pudendal nerve (a somatic nerve) carries afferents from the distal urethra, urethral sphincter, and perineum. Since the DCM region exhibits the highest percentage of c-fos-positive cells induced by either pelvic or pudendal afferents, it is likcly that this arca is important for viscerosomatic interactions and for processing of nociceptive information from different parts of the LUT. On the other hand, the SPN and MDH areas exhibit more specificity and seem to be important for processing visceral and somatic inputs, respectively.

This view is also supported by differences in the distribution of c-fos cells induced by other stimuli to the LUT. For example, introduction of a urethral catheter increased c-fos primarily in the MDH (42.9\%) and DCM (40.9\%) regions. In unpublished experiments, we noted that ligation of the urethral orifice without insertion of the catheter induced c-fos primarily in the $\mathrm{MDH}$ region ( $84 \%$ of the cells), indicating that this area receives a prominent input from the distal urethra presumably via pudendal nerve afferents. In the same experiments, insertion of a catheter followed by ligation of the urethral orifice, which should activate afferent input from bladder neck as well as distal and proximal urethra, activated similar percentages of cells in the $\mathrm{MDH}(43 \%)$ and DCM (45\%) regions. These observations raise the possibility that distal urethral inputs project to $\mathrm{MDH}$ and proximal urethra inputs project primarily to DCM.

The number of c-fos-positive cells attributed to afferent input from bladder tension receptors was estimated by subtracting the number of cells produced by catheter alone. This method indicated that distension of the bladder produced a large percentage of cells in the SPN (41.1\%) and DCM (44\%) and a smaller percentage in the MDH (12.1\%) region (Fig. 9, Table 1). The total number of c-fos-positive cells in MDH was similar to that induced by catheter alone. This suggests that tension receptor afferents activated by distension of the bladder or by reflex bladder contractions preferentially activates cells in the SPN and DCM. Using a similar approach, it was estimated that 
chemical irritation of the LUT also activated cclls in all four spinal regions, with the largest percentage in the DCM region (48\%) followed in descending order by the MDH (27.1\%), LDH (15.4\%), and SPN (9.5\%). These results suggest that the DCM area may be important in processing information concerning nociception as well as distension in the LUT.

The convergence of inputs from different types of afferents (nociceptive and mechanoreceptive) and from different areas of the LUT (bladder and urethra) to the same regions of the spinal cord raises a number of potential complications in interpreting the data particularly when estimating the size and distribution of certain populations of cells by subtracting the number of cells activated by one stimulus from that induced by a combination of stimuli. For example, this approach does not take into account convergence of two inputs onto the same population of cells, which could produce synergistic interactions (i.e., either input alone is ineffective in activating c-fos but two inputs acting synergistically induce gene expression) or occlusion where two inputs both maximally activate c-fos expression. Physiological experiments indicate that different stimuli do interact to influence micturition (Maggi et al., 1988; Morikawa et al., 1990). Since nociceptive stimuli facilitate bladder reflexes, nociceptive input from the urethra (via introduction of a catheter) (Abelli et al., 1991) could modulate the expression of $c$-fos induced by physiological distension of the bladder. In addition, different afferent inputs from the LUT elicited by distension or nociceptive stimuli can initiate reflex bladder contractions, which can in turn activate mechanoreceptor afferents. Thus, the presence of a reflex loop in animals with an intact nervous system could complicate the analysis of the effects of specific afferent pathways on c-fos expression. A more ideal experimental paradigm would allow the effect of each type of stimulus to be examined in isolation. Howcver, this was not possible in the present cxpcriments since catheterization and fluid distension of the bladder were necessary to induce chemical irritation.

Supraspinal micturition reflex pathways are essential for the control of bladder activity and the initiation of voiding (de Groat, 1975; de Groat and Steers, 1990). To determine if an intact supraspinal reflex has a role in the activation of c-fos in spinal cord neurons during LUT irritation, spinal-transected rats were studied. Following transection, the bladder was areflexic before and after a $1 \%$ acetic acid was introduced via a transurethral catheter. However, irritation (both catheterization and chemical irritation) induced $\mathrm{c}$-fos in the same spinal cord areas as in the intact preparation (DCM, $47.4 \pm 5.1 \% ; \mathrm{MDH}$, $23.7 \pm 4.5 \% ; \mathrm{SPN}, 22.8 \pm 1.9 \%$;DH, $5.8 \pm 1.7 \%)$. In these experiments, the number of c-fos-positive cells was less but the reduction was not statistically significant. The fact that the bladder was areflexic in the spinal-transected preparation indicates that the supraspinal reflex that is essential for voiding is not necessary for the increased expression of c-fos by chemical irritation. This suggests that $\mathrm{c}$-fos is expressed in spinal neurons via an increase in primary afferent input and segmental synaptic mechanisms.

Experiments were conducted to determine if activation of serosal afferents via a chemical irritant could increase the expression of $\mathrm{c}$-fos at the spinal level. It has been shown that capsaicin applied to the surface of the urinary bladder produces an increase in motility and an inflammatory reaction (increase in plasma extravasation) that is localized to the bladder neck and urethra (Maggi et al., 1987). Application of 1\% acetic acid or capsaicin solution onto the serosal surface of the urinary bladder did not increase the expression of $\mathrm{c}$-fos in spinal cord neurons, whereas irritation of the mucosal surface of the urinary bladder did increase c-fos. In studies in which $9 \%$ acetic acid was injected into the peritoneal cavity of the rat (Menetrey et al., 1989), a large number of nociceptive afferents were presumably activated, including serosal afferents from the urinary bladder. C-fos expression was slightly increased in the superficial dorsal horn at the $\mathrm{L}_{6} / \mathrm{S}_{1}$ level, but was markedly increased at the level of the caudal thoracic and rostral lumbar segments in the dorsal horn (superficial and deep areas) and in lamina $\mathrm{X}$, regions that are implicated in nociceptive processing. These observations are consistent with the present negative results with bladder serosal irritation in the $\mathrm{L}_{6}-\mathrm{S}_{1}$ segments and suggest a difference in the spinal mechanisms for processing inputs from serosal and mucosal nociceptive afferents.

Noxious and non-noxious stimulation of the colon and rectum of the rat induced by distension with graded pressures $(20$ $80 \mathrm{~mm} \mathrm{Hg}$ ) increases $c$-fos expression in the $\mathrm{L}_{5}-\mathrm{S}_{1}$ segments of the spinal cord (Traub and Gebhardt, 1990). Similar to the present results, more intense colonic stimuli produced greater numbers of c-fos-positive cells, and the cells were located bilaterally in laminae I, II, V, VI, and X and the region of the SPN. It is interesting, however, that in the superficial dorsal horn (laminae I and II), colonic distension induced the largest number of cells in the lateral region, whereas LUT irritation produced a larger number in the $\mathrm{MDH}$. This difference might be explained in part by the effect of urinary tract irritation to activate pelvic and pudendal afferents. The latter are known to terminate in the MDH (Thor et al., 1989). On the other hand, colon-rectal distension primarily activates visceral afferents in the pelvic nerve, which have a prominent projection to the LDH (Nadelhaft and Booth, 1984; Steers et al., 1991).

Noxious stimulation of the LUT and colon induced c-fos expression in a small number of cells in lamina II. This is inconsistent with electrophysiological experiments that have indicated that cells in lamina II are unresponsive to visceral afferent input, but is consistent with anatomical tracing studies (Morgan et al., 1981; Sugiura et al., 1989) that have identified visceral afferent terminations in lamina II. These differences might be explained by an effect of weak synaptic inputs to increase gene expression but not increase cell firing. In addition, LUT irritation activates urethral afferents in the pudendal nerve. Afferents in this somatic nerve are known to project to deeper laminae of the dorsal horn (Thor et al., 1989).

The distribution of c-fos-positive neurons induced by LUT irritation differed from that induced by activation of somatic afferents (footpaw), in which c-fos-positive neurons were located in $\mathrm{L}_{4}-\mathrm{L}_{5}$ spinal segments ipsilateral to the site of stimulation throughout laminae I-V of the dorsal horn (Fig. 8). The latter distribution corresponds to that seen by other investigators (Menetrey et al., 1989; Bullitt, 1990) and indicates that urethane anesthesia does not produce a quantitative or qualitative difference in c-fos expression. These observations also indicate that neurons in laminae III and IV receive primarily inputs from somatic receptive fields whereas neurons in lamina $\mathrm{I}$ and $\mathrm{V}$ receive convergent inputs from visceral as well as somatic structures (Cervero and Tattersall, 1986).

In summary, the measurement of c-fos gene expression in spinal neurons has provided new insights into the central processing of afferent input from the LUT of the rat. The present results indicate that nociceptive and non-nociceptive afferent pathways from the urinary bladder and urethra activate neurons 
in similar regions of the spinal cord. However, there were also differences in the relative distributions of cells according to the stimulus modality. The types of neurons that express $c$-fos in response to LUT irritation are unknown; however, the laminar distribution of these neurons suggests that they may participate in voiding reflexes and in nociceptive processing, and therefore may be part of ascending projection systems to the pontine micturition center and to the thalamus. This is supported by other studies (Birder et al., 1990) indicating that a percentage of the cells that are c-fos positive after bladder irritation are spinal tract neurons projecting to the brain.

\section{References}

Abelli L, Conte B, Somma V, Parlani M, Geppetti P, Maggi CA (1991) Mechanical irritation induces neurogenic inflammation in the rat urethra. J Urol 146:1624-1626.

Birder LA, Roppolo JR, Iadarola MJ, de Groat WC (1989) Spinal cord distribution of $\mathrm{c}$-fos protein in visceral versus somatic models of chemical irritation. Soc Neurosci Abstr 15:468.

Birder LA, Roppolo JR, Iadarola MJ, de Groat WC (1990) C-fos as a marker for subsets of visceral second order neurons in the rat lumbosacral spinal cord. Soc Neurosci Abstr 16:703.

Bullitt E (1990) Expression of c-fos-like protein as a marker for neuronal activity following noxious stimulation in the rat. J Comp Neurol 296:517-530.

Cervero F, Tattersall IEM (1986) Somatic and visceral sensory integration in the thoracic spinal cord. Prog Brain Res 67:189-205.

Chi S-I, Levine JD, Basbaum AJ (1990) Effects of baclofen and morphine on the persistent expression of $c$-fos in rat spinal cord following peripheral nerve injury. Soc Neurosci Abstr 16:566.

Curran T (1988) The fos oncogene. In: The oncogene handbook (Reddy EP, Skalka AM, eds), pp 307-327. Elsevier: Amsterdam.

de Groat WC (1971) Excitation and inhibition of sacral parasympathetic neurons by visceral cutaneous stimulation in the cat. Brain Res 33:499-503.

de Groat WC (1975) Nervous control of the urinary bladder of the cat. Brain Res 87:201-211.

de Groat WC (1986) Spinal cord projections and neuropeptides in visceral afferent neurons. In: Visceral sensation, Prog Brain Res, Vol 67, Chap 11 (Cervero F, Morrison JFB, eds), pp 165-168. Amsterdam: Elsevier.

de Groat WC, Steers WD (1990) Autonomic regulation of the urinary bladder and sex organs. In: Central regulation of autonomic functions, Chap 17 (Loewy AD, Spyer KM, eds), pp 310-333. New York: Oxford UP.

de Groat WC, Booth AM, Krier J, Milne RJ, Morgan C, Nadelhaft I (1979) Neural control of the urinary bladder and large intestine. In: Integrative functions of the autonomic nervous system, Vol 4 (Brooks CM, Koizumi K, Sata K, eds), pp 50-67. Tokyo: University of Tokyo.

de Groat WC, Nadelhaft I, Milne RJ, Booth AM, Morgan C, Thor K (1981) Organization of the sacral parasympathetic reflex pathway to the urinary bladder and large intestine. J Auton Nerv Sys 4:135-160.

de Groat WC, Kawatani M, Hisamitsu T, Booth AM, Roppolo JR, Thor K, Tuttle P, Nagel J (1986) Neural control of micturition: the role of neuropeptides. J Auton Nerv Sys [Suppl] 369-387.

Fall M, Lindstrom S, Mazieres L (1990) A bladder-to-bladder cooling reflex in the cat. J Physiol (Lond) 427:281-300.

Habler HJ, Janig J, Koltzenburg M (1990) Activation of unmyelinated afferent fibres by mechanical stimuli and inflammation of the urinary bladder in the cat. J Physiol (Lond) 425:545-562.

Hohlbrugger G, Lentsch P (1985) Intravesical ions, osmolarity and $\mathrm{pH}$ influence the volume pressure response in the normal rat bladder, and this is more pronounced after DMSO exposure. Eur Urol 11: $127-130$.

Honda CN (1985) Visceral and somatic afferent convergence onto neurons near the central canal in the sacral spinal cord of the cat. $J$ Neurophysiol 53:1059-1078.

Horita AJ, Weber J (1964) Skin penetrating property of drugs dissolved in dimethyl sulfoxide (DMSO) and other vehicles. Life Sci 3:1389.

Hsu SM, Raine L, Fanger H (1981) Use of avidin-biotin-peroxidase complex $(\mathrm{ABC})$ in immunopcroxidase techniques. A comparison between ABC and unlabelled antibody (PAP) procedure. J Histochem Cytochem 29:1349-1353.
Hunt SP, Pini A, Evan G (1987) Induction of c-fos-like protein in spinal cord neurons following sensory stimulation. Nature 328:632634.

Janig W, Koltzenburg M (1990) On the function of spinal primary afferent fibres supplying colon and urinary bladder. J Auton Nerv Sys 30:S89-S96.

Janig W, Morrison JFB (1986) Functional properties of spinal visceral afferents supplying abdominal and pelvic organs, with special emphasis on visceral nociception. Prog Brain Res 67:87-113.

Jansco G, Maggi CA (1987) Distribution of capsaicin-sensitive urinary bladder afferents in rat spinal cord. Brain Res 418:371-376.

Jenkins R, Hunt SP (1991) Long-term increase in the levels of c-jun mRNA and jun protein-like immunoreactivity in motor and sensory neurons following axon damage. Neurosci Lett 129:107-1 10.

Jones SL, Light AR (1990) Electrical stimulation in the medullary nucleus raphe magnus inhibits noxious heat-evoked fos protein-like immunoreactivity in the rat lumbar spinal cord. Brain Res 530:335338.

Keast JR, de Groat WC (1992) Segmental distribution and peptide content of primary afferent neurons innervating the urogenital organs and colon of male rats. J Comp Neurol 319:615-623.

Kruse MN, Noto H, Roppolo JR, de Groat WC (1990) Pontine control of the urinary bladder and external urethral sphincter in the rat. Brain Res 532:182-190.

Kuru M (1965) Nervous control of micturition. Physiol Rev 45:425494.

Luna L (1968) Manual of histological staining methods of the armed forces institute of pathology. New York: McGraw-Hill.

Maggi CA, Santicioli P, Meli A (1986) Somatovesical and vesicovesical excitatory reflexes in urethane anesthetized rats. Brain Res 380: 83-89.

Maggi CA, Santicioli P, Abelli L, Parlani M, Capasso M, Conte B, Giuliani S, Meli A (1987) Regional differences in the effects of capsaicin and tachykinins on motor activity and vascular permeability in the rat lower urinary tract. Naunyn Schmiedebergs Arch Pharmacol 335:636-645.

Maggi CA, Abelli L, Giuliani S, Santicioli P, Geppetti P, Somma V, Frilli S, Meli A (1988) The contribution of sensory nerves to xyleneinduced cystitis in rats. Neuroscience 26:709-723.

Mallory B, Steers W, de Groat WC (1989) Electrophysiological study of micturition reflexes in rats. Am J Physiol 257:R410-R422.

McKenna KE, Nadelhaft I (1986) The organization of the pudendal nerve in the male and female rat. J Comp Neurol 248:532-549.

McMahon SB, Morrison JFB (1982a) Two groups of spinal interneurones that respond to stimulation of the abdominal viscera of the cat. J Physiol (Lond) 322:21-34.

McMahon SB, Morrison JFB (1982b) Spinal neurones with long projections activated from abdominal viscera of the cat. J Physiol (Lond) 322:1-20.

Menetrey P, Gannon A, Levine JD, Basbaum AI (1989) Expression of c-fos protein in interneurons and projection neurons in the rat spinal cord in response to noxious somatic, articular and visceral stimulation. J Comp Neurol 285:177-195.

Morgan C, Nadelhaft I, de Groat WC (1981) The distribution of visceral primary afferents from the pelvic nerve to Lissauer's tract and spinal grey matter and its relationship to the sacral parasympathetic nucleus. J Comp Neurol 201:415-440.

Morikawa K, Fukuoka M, Kakiuchi M, Kato H, Ito Y, Gomi Y (1990) Detrusor hyperreflexia induced by intravenous instillation of xylene in conscious rats. Jpn J Pharmacol 52:587-595.

Nadelhaft I, Booth AM (1984) The location and morphology of preganglionic neurons and the distribution of visceral afferents from the rat pelvic nerve: a horseradish peroxidase study. J Comp Neurol 226 : 238-245.

Perzin A, Hanno P, Ruggieri M (1991) Effect of protamine and interstitial cystitis urine on dye penetration across the rabbit urothelium. J Urol 145:185.

Sagar SM, Sharp FR (1990) Light induces a Fos-like nuclear antigen in retinal neurons. Mol Brain Res 7:17-21.

Sagar SM, Sharp FR, Curran T (1988) Expression of c-fos protein in brain: metabolic mapping at the cellular level. Science 240:13281331.

Santicioli P, Maggi CA, Meli A (1986) Functional evidence for the existence of a capsaicin-sensitive innervation in the rat urinary bladder. J Pharm Pharmacol 38:446-451.

Sassone-Corsi P, Lamph WW, Verma IM (1988) Regulation of proto- 
oncogene fos: a paradigm for early response genes. Cold Spring Harbor Symp Quant Biol 53:749-760.

Sharkey KA, Williams RG, Schultzberg M, Dockray GJ (1983) Sensory substance P-innervation of the urinary bladder: possible site of action of capsaicin in causing urine retention in rats. Neuroscience 10:861-868.

Sharp FR, Griffith J, Gonzalez MF, Sagar SM (1989) Trigeminal nerve section induces Fos-like immunoreactivity (FLI) in brainstem and decreases FLI in sensory cortex. Mol Brain Res 6:217-220.

Sharp FR, Sagar SM, Hicks K, Lowenstein D, Hisanaga K (1991) cfos mRNA, Fos and Fos-related antigen induction by hypertonic saline and stress. J Neurosci 11:2321-2331.

Sonnenberg JL, Macgregor-Leon PF, Curran T, Morgan JI (1989) Dynamic alterations occur in the levels and composition of transcription factor AP-1 complexes after seizure. Neuron 3:359-365.

Steers WD, Ciambotti J, Etzel B, Erdman S, de Groat WC (1991) Alterations in afferent pathways from the urinary bladder of the rat in response to partial urethral obstruction. J Comp Neurol 310:401410.

Sugiura Y, Terui N, Hosoya Y (1989) Difference in distribution of central terminals between visceral and somatic unmyelinated (C) primary afferent fibers. J Neurophysiol 62:834-840.

Thor K, Morgan C, Nadelhaft I, Houston M, de Groat WC (1989) Organization of afferent and efferent pathways in the pudendal nerve of the female cat. J Comp Neurol 288:263-279.

Traub RJ, Gebhardt GF (1990) Noxious and non-noxious colorectal distension results in c-fos induction in the rat spinal cord. Soc Neurosci Abstr 16:704.

Weinberg RA (1985) The action of oncogenes in the cytoplasm and nucleus. Science 230:770-776.

Young ST, Porrino LJ, Iadarola MJ (1991) Cocaine induces striatal c-fos-immunoreactive proteins via dopaminergic D1 receptors. Proc Natl Acad Sci IJSA 88:1291-1295. 